\title{
Forma de presentación de una amiloidosis primaria como polimialgia reumática y arteritis de células gigantes
}

\author{
L. PANTOJA ZARZA, J. PANIAGUA DE LA RIVA*, M. MEGIDO LAHERA**, \\ J. ORTIZ DE SARACHO*** \\ Unidad de Reumatología. *Sección de Nefrología. **Sección de Hematología. \\ ***Unidad de Neumología. Hospital del Bierzo. Ponferrada. León
}

PRIMARY SYSTEMIC AMYLOIDOSIS PRESENTING AS POLYMIAL GIA RHEUMATICA AND GIANT CELL ARTERITIS

\section{RESUMEN}

La amiloidosis primaria o amiloidosis AL es una discrasia de células plasmáticas difícil de diferenciar del mieloma múltiple, que se caracteriza por el depósito de una proteína fibrilar de cadenas ligeras monoclonales en tejidos y órganos. Es una enfermedad poco frecuente, en la que un clon de células plasmáticas en la médula ósea produce inmunoglobulinas amiloidogénicas. En el 90\% de los casos se detecta por inmunoelectroforesis inmunoglobulinas monoclonales en sangre $\mathrm{u}$ orina. Habitualmente se manifiesta como insuficiencia cardiaca, síndrome nefrótico o neuropatía periférica, pero excepcionalmente pueden existir síntomas sugestivos de arteritis de células gigantes (ACG) o polimialgia reumática (PMR). Aunque el número de clones de células plasmáticas en la médula ósea suele ser pequeño, la actitud terapeútica es la de una enfermedad proliferativa maligna, siendo la supervivencia media de 12 a 15 meses. Presentamos un paciente cuya primera manifestación de amiloidosis primaria fueron síntomas de ACG y PMR, y revisamos las principales características de esta enfermedad.

PALABRAS CLAVE: Amiloidosis primaria. Arteritis de células gigantes. Polimialgia reumática.

\section{ABSTRACT}

Primary systemic amyloidosis or AL-amyloidosis is an uncommon disease characterized by the accumulation in vital organs of a fibrillar protein consisting of monoclonal light chains. It is a plasma-cell dyscra sia related to multiple myeloma where clonal plasma cells in the bone marrow produce immunoglobulins that are amyloidogenic. A monoclonal component is present in the serum or urine of $90 \%$ of patients. The pre sentation of most patients with AL amyloidosis is usually related to congestive heart failure, nephrotic syndrome o peripheral neuropathy, but there are unusual features suggesting giant cell arteritis (GCA) and polymyalgia rheumatic (PMR). Although in the majority of AL cases the plasma cells clone is small, the assumption is that the outcome of the dise ase is uniformly fatal (median survival 12-15 months) and treatment is analogous to those used in malignant proliferative disease. We describe a patient with AL amyloidosis who presented with manifestations of GCA and PMR, and we review the main characteristics of primary amyloidosis.

KEY WORDS: Primary systemic amyloidosis. Giant cell artritis. Polymyalgia rheumatica.

Pantoja Zarza L, Paniagua de la Riva J, Megido Lahera M, Ortiz de Saracho J. Forma de presentación de una amiloidosis primaria como polimialgia reumática y arteritis de células gigantes. An Med Interna (Madrid) 2001; 18: 205-207.

\section{INTRODUCCIÓN}

El término amiloidosis no se refiere a una única enfermedad sino a un grupo de entidades que comparten el hallazgo del depósito patológico extracelular de proteínas fibrilares insolubles en tejidos y órganos. La amiloide se tiñe con rojo Congo adoptando una birrefringencia verde con luz polarizada. La clasificación actual de la amiloidosis se basa en la naturaleza del precursor de las proteínas plasmáticas que forman los depósitos fibrilares (1) (Tabla I). La amiloidosis primaria o amiloidosis AL es una disproteinemia infrecuente (8 casos por millón de personas por año), cuya manifestación clínica es muy variada, pudiendo en ocasiones presentar síntomas que sugieran una vasculitis. Excepcionalmente la clínica de arteritis de células gigantes (ACG) y/o de polimialgia reumática (PMR) puede ser la primera manifestación. Presentamos el caso de un paciente que se le diagnosticó de amiloidosis AL cuyos primeros síntomas fueron sugestivos de una ACG y PMR, y que presentó una evolución fatal en menos de 3 meses desde el inicio de la clínica.

\section{CASO APORTADO}

Varón de 74 años, de profesión tapicero jubilado, fumador de 20 cigarrillos/día hasta los 50 años, bebedor moderado, diagnosticado de ulcus gastroduodenal 10 años antes. Acude a consulta por claudicación de miembros inferiores tras andar 10 metros, de mes y medio de evolución, sin disestesias ni disfunción eréctil, y parestesias en $4^{\circ}$ y $5^{\circ}$ dedos de ambas manos. En las últimas dos semanas se había añadido clínica de claudicación mandibular, junto con dolor y dificultad para movilizar la columna cervical y la cintura escapular. A la exploración destacaba un buen estado general, TA 100/60, arrítmico a $140 \mathrm{lpm}$, soplo sistólico I/VI en zona paraesternal izquierda y crepitantes de despegamiento en base izquierda. Los pulsos de las extremidades superiores eran normales pero no se palpaban los pulsos pedios ni tibiales. Las arterias temporales latían simétricas. Existía dificultad para la elevación de brazos y para levantarse de la silla, con fuerza y exploración neurológica normal, y no se objetivaba sinovitis. Los signos de Tinel y Phalen bilateral eran negativos y el fondo de ojo era normal. En la analítica destacaba $\mathrm{Hb} 119 \mathrm{~g} / \mathrm{l}$, Hto 0,35 l/1, VCM 106,9 fL, HCM 36,1 fL, VSG $63 \mathrm{~mm} / \mathrm{h}$, urea 104 $\mathrm{mg} / \mathrm{dl}$ y creatinina $4,8 \mathrm{mg} / \mathrm{dl}$, proteínas totales $6,4 \mathrm{~g} / \mathrm{dl}$. El ECG objetivó una fibrilación auricular a $140 \mathrm{lpm}$. En la Rx de tórax se

Trabajo aceptado: 12 de Junio de 1999

Correspondencia: L. Pantoja. Pl. Fernando Miranda 10. 24400 Ponferrada (León). 


\section{TABLA I}

\begin{tabular}{|c|c|c|}
\hline \multicolumn{3}{|c|}{ TABLA I } \\
\hline \multicolumn{3}{|c|}{ CLASIFICACIÓN DE LA AM ILOIDOSIS } \\
\hline Tipo & Composición depósito fibrilar & Proteína precursora \\
\hline AL (primaria) & $\begin{array}{l}\text { Cadenas ligeras de inmunoglo- } \\
\text { bulinas monoclonales }\end{array}$ & Cadenas ligeras $\lambda 0 \mathrm{~K}$ \\
\hline $\begin{array}{l}\text { ATTR (familiar) } \\
\text { AA (secundaria) }\end{array}$ & $\begin{array}{l}\text { Transtirretina } \\
\text { Proteína amiloide A }\end{array}$ & $\begin{array}{l}\text { Transtirretina anorma } \\
\text { Proteína amiloide A }\end{array}$ \\
\hline $\begin{array}{l}\text { Otros tipos familia } \\
\text { AApoA-I } \\
\text { Agel } \\
\text { A Fib } \\
\text { Alys }\end{array}$ & $\begin{array}{l}\text { Apolopoprotina A-I } \\
\text { Gelsolina } \\
\text { Fibrinógeno A } \alpha \\
\text { Lisozima }\end{array}$ & $\begin{array}{l}\text { Apo A-I } \\
\text { Gelsolina } \\
\text { Fibrinógeno A } \alpha \\
\text { Lisozima }\end{array}$ \\
\hline
\end{tabular}

observaba cardiomegalia. La ecografía abdominal visualizó un riñón derecho con un quiste en polo superior de $51 \mathrm{~mm}$ y el riñón izquierdo de tamaño normal. En el ecodoppler no se apreció ateromatosis significativa, siendo los flujos arteriales a todos los niveles de características normales. En las Rx de columna cervical y lumbar se observaban signos de hiperostosis esquelética idiopática difusa (HEID) y pinzamiento en L5-S1. La TAC lumbar confirmó los signos de HEID y la degeneración y herniación del disco L5-S1. Se realizó biopsia de la arteria temporal, iniciándose tratamiento empírico con esteroides, sin respuesta clínica, por lo que al recibir el resultado de la biopsia compatible con arteriosclerosis se suspendieron, y se procedió al ingreso para completar el estudio. En el resto de pruebas destacaba: proteinograma normal, ligero descenso de IgG, IgA e IgM en sangre; marcadores tumorales (alfafetoproteína, PSA y CEA) negativos; serología para VHB, VHC, VIH, RPR, CMV, negativas; y TSH, PTH, vitamina B12 y ácido fólico, normal. Los ANA, ANCA y anticuerpos antimembrana basal fueron negativos, así como el Mantoux. En el análisis de orina se obtuvo proteinuria $4 \mathrm{~g} / 24$ horas, creatinina $38,57 \mathrm{mg} / \mathrm{dl}$, urea $566 \mathrm{mg} / \mathrm{dl}$, y sedimento con más de 50 hematíes. IEF orina: intensa banda de aspecto monoclonal de cadenas ligeras k. Realizada una biopsia de grasa abdominal, se solicitó además tinción de rojo congo en la muestra arterial biopsiada previamente, objetivándose en ambas depósitos de amiloide. En el ecocardiograma se visualizaba una aurícula izquierda dilatada, válvula mitral con velos de aspecto mixomatoso, con movimiento muy amplio e insuficiencia moderada; válvula aórtica de aspecto degenerativo con insuficiencia leve. El ventrículo izquierdo era de tamaño, grosor y contractilidad normales, con fracción de eyección $72 \%$. La gastroendoscopia mostró una esofagitis moderada con úlcera marginal, ulcus gástrico de aspecto benigno, duodenitis erosiva y gastritis crónica atrófica con $H$. pylori. En la TAC toracoabdominal se observaba un nódulo con calcio de $1 \mathrm{~cm}$ en base pulmonar izquierda, en relación probable con granuloma; granulomas calcificados en lóbulos hepáticos y en corteza renal derecha un quiste de $5 \mathrm{~cm}$ de diámetro, con calcificación curvilínea en su porción externa. El EMG para valoración de túnel carpiano y sistema nervioso autónomo objetivó afectación de fibras motoras de ambos nervios medianos a nivel del carpo, con importante afectación de fibras simpáticas colinérgicas; disminución de glándulas sudoríparas a nivel de mano y pie, y ausencia de variación significativa de la TA sistólica con la sedestación. La espirometría era compatible con restricción leve. El estudio de médula ósea mostró una celularidad global aumentada con un $27 \%$ de células plasmáticas con morfología atípica. La serie ósea radiológica fue normal. Se inició tratamiento con un primer ciclo de Melfalán y Prednisona. Durante el ingreso presentó un deterioro progresivo de la función renal, hipotensión ortostática, episodios de diarrea, disfonía moderada, disfagia para sólidos y líquidos, y tos incoercible. A las dos semanas de su estancia hospitalaria presentó oligoanuria, con creatinina $9,9 \mathrm{mg} / \mathrm{dl}$ y urea $239 \mathrm{mg} / \mathrm{dl}$, entrando en hemodiálisis, falleciendo una semana después por parada cardiorrespiratoria.

\section{DISCUSIÓN}

La amiloidosis AL es una discrasia de células plasmáticas relacionada con el mieloma múltiple (MM), en donde los clones de células plasmáticas de la médula ósea producen inmunoglobulinas que son amiloidogénicas. Las fibrillas de amiloide AL provienen de los residuos de aminoácidos de la región $\mathrm{N}$ terminal del dominio variable de una cadena ligera monoclonal. En la amiloidosis AL el tipo de cadena ligera $\lambda$ es más frecuente que $\mathrm{k}(2: 1)$, en contraste con las clases de cadenas ligeras del MM en donde la proporción es al revés. El análisis secuencial de proteínas de Bence-Jones sugiere que las cadenas ligeras "amiloidogénicas" tienen sustituciones específicas de aminoácidos en comparación con las "no-amiloidogénicas" (2).

La amiloidosis AL puede ser dividida en amiloidosis AL y en amiloidosis AL con MM, en base al número de células plasmáticas de la médula ósea, la cantidad de proteína monoclonal en suero u orina y a la presencia o ausencia de lesiones óseas. Sin embargo diferenciar si existe o no MM es, en muchas ocasiones difícil y artificial, pues ambos son procesos de proliferación clonal de células plasmáticas y por tanto muchas veces solapados, por lo que es preferible considerar ambas categorías juntas como amiloidosis AL (3).

Las manifestaciones clínicas en la amiloidosis AL reflejan la afectación multisistémica de la enfermedad, pues los depósitos de amiloide se encuentran virtualmente en todos los órganos excepto en el sistema nervioso central. Los órganos más frecuentemente afectados son el riñón y el corazón. La amiloidosis AL renal se manifiesta con proteinuria, y con frecuencia con un síndrome nefrótico. Durante el curso de la enfermedad un tercio de los pacientes precisan diálisis en un periodo aproximado de 13,8 meses desde el diagnóstico (4). Es raro el hallazgo de hipertensión arterial a pesar de los niveles elevados de creatinina, y el grado de proteinuria no se correlaciona con la extensión de los depósitos amiloideos en los riñones, los cuales suelen ser de tamaño normal.

La insuficiencia cardiaca, habitualmente de inicio rápido y progresivo, puede estar precedida por anomalías en el ECG. Este suele mostrar un bajo voltaje o hallazgos de infarto anteroseptal en ausencia de enfermedad coronaria. Las arritmias, incluyendo la fibrilación auricular, como la detectada en nuestro paciente, también son hallazgos comunes. El ecocardiograma suele mostrar un engrosamiento concéntrico de las paredes de los ventrículos con una fracción de eyección normal o moderadamente reducida, y una disfunción diastólica, con un patrón restrictivo en las fases avanzadas con repercusión hemodinámica. Esto puede causar claudicación intermitente en brazos y piernas, y contribuir a la hipotensión ortostática que aparece en el $11 \%(1,3)$.

En contraste con la ausencia de afectación del sistema nervioso central, la neuropatía sensitivomotora y autonómica es un hallazgo frecuente. La clínica de síndrome de tunel carpiano es la manifestación inicial en el $20 \%$ de los pacientes, y puede preceder a la enfermedad en más de un año (1). La neuropatía suele ser sensitiva, distal, simétrica y progresiva. La disfunción autonómica se manifiesta como hipotensión ortostática, diarrea o impotencia. El tracto gastrointestinal, con frecuencia infiltrado con amiloide, raramente está asociado a malabsorción, y se detecta hepatomegalia en una cuarta parte de los pacientes. Aunque histológicamente se detecta amiloide en los pulmones, suele ser asintomático, o producir tos, a la cual pueden contribuir también la infiltración de laringe y traquea. La macroglosia ocurre en el $10 \%$ de los pacientes, y se puede acompañar de un 
aumento del tamaño de las glándulas submandibulares, contribuyendo a la obstrucción respiratoria. La infiltración de las cuerdas vocales produce alteraciones en la voz $(1,3)$.

La claudicación mandibular se considera muy específico de la ACG. Sin embargo los depósitos de amiloide en la arteria temporal fueron observados hace más de 40 años, aunque los síntomas habitualmente no se reconocen (5). En 1986 Gertz et al., tras comunicar dos pacientes con clínica de claudicación mandibular y sospecha de ACG que se les diagnosticó de amiloidosis AL, revisan 237 casos de amiloidosis sistémica diagnosticados en un periodo de 11 años, y encuentran una frecuencia de claudicación mandibular del $9 \%$, siendo un síntoma que habitualmente se asocia a otros de isquemia vascular, como la claudicación de miembros (6). En esta serie los pacientes con claudicación mandibular tenían una supervivencia mayor que el resto de los pacientes (42 meses frente a 12 meses), presumiblemente por la afectación fundamentalmente vascular y la falta de extensión a órganos críticos. En una proporción menor se han descrito algunos casos en donde la amiloidosis AL presentaba clínica de PMR, generalmente con síntomas de ACG acompañantes, y en donde el empleo de esteroides mejoraba los síntomas articulares aunque no la claudicación mandibular (6-9).

En pacientes con amiloidosis AL se detectan inmunoglobulinas monoclonales por inmunoelectroforesis de sangre $\mathrm{u}$ orina en el $90 \%$ de los casos. La realización de la biopsia y aspirado de médula ósea es necesaria para determinar el número de células plasmáticas y su monoclonalidad. En la mayoría de los casos de amiloidosis AL el número de clones es pequeño ( $<10 \%$ de células plasmáticas en la médula ósea), pero la actitud terapeútica es la de una enfermedad proliferativa maligna, pues la distinción entre la existencia de un MM sobre una amiloidosis AL es arbitraria y la evolución es habitualmente fatal.

En la extensa experiencia del grupo de la Clínica Mayo sobre 400 casos de amiloidosis AL la supervivencia media es de 12-15 meses, y menor si se asocia a MM (3). Aproximadamente en la mitad de los casos la causa de la muerte es de origen cardiaco, y cuando en el momento del diagnóstico existe insuficiencia cardiaca, la supervivencia es sólo de 6 meses. El tratamiento tiene como objetivo suprimir el clon de células B, y por tanto la producción del precursor de la amiloide. Sin embargo las discrasias de células plasmáticas de bajo grado pueden ser menos quimiosensibles que el MM y difícil de monitorizar; además gran parte de los pacientes tienen una enfermedad tan avanzada en el momento del diagnóstico que el tratamiento citostático no puede mostrar su efectividad (4).

El único régimen terapeútico que ha sido evaluado en ensayos clínicos es el empleo de melfalán y prednisona. En el primer estudio con 55 pacientes, de 24 sujetos con síndrome nefrótico la proteinuria se resolvía en 2 pacientes y se reducía más del $50 \%$ en 8 (10). Estos resultados fueron posteriormente confirmados por Gertz et al. en 153 pacientes con amiloidosis AL, tratados con melfalán y prednisona durante un máximo de 36 meses, el 18\% respondió en el primer año; la supervivencia media de los respondedores fue de 89 meses, con el $78 \%$ del grupo vivos a los 5 años. Los no respondedores tuvieron una supervivencia media de 15 meses. El mayor grado de respuesta (39\%) se obtuvo en pacientes con síndrome nefrótico, con creatinina normal y sin evidencia ecocardiográfica de amiloidosis cardiaca (11). Sin embargo el 6,5\% de los pacientes tratados desarrollaron leucemia o un síndrome dismielopoyético por la exposición prolongada al melfalán, por lo que aunque actualmente se recomienda al menos 12 meses de tratamiento, la duración óptima de este está por determinar.

El empleo de colchicina ha sido examinado exhaustivamente en un estudio de 220 pacientes tratados con colchicina como única droga; melfalán y prednisona; o melfalán, prednisona y colchicina. La supervivencia media fue de 8,5, 17 y 16 meses respectivamente, por lo que la colchicina no aporta ningún beneficio a la amiloidosis AL (12).

Se han intentado otros regímenes terapeúticos como los empleados en el MM con vincristina, adriamicina y dexametasona; altas dosis de quimioterápicos; interferón- $\alpha 2 \beta$, pero sin evidencias objetivas de respuesta clínica o de regresión de la enfermedad $(2,4,13)$.

Aunque el tratamiento de la amiloidosis AL no es satisfactorio, una proporción significativa de pacientes pueden beneficiarse de la quimioterapia. Para ello es de vital importancia el diagnóstico temprano, pues los estadios precoces son los más susceptibles al mismo. De ahí el interés de reconocer las manifestaciones clínicas menos características, como los síntomas de PMR y/o ACG. Creemos que es aconsejable la tinción con rojo Congo de las muestras de biopsia de arteria temporal para asegura el diagnóstico correcto, especialmente en pacientes con una banda monoclonal en la inmunoelectroforesis o en aquellos que no responden a esteroides.

\section{Bibliografía}

1. Falk RH, Comenzo RL, Skinner M. The systemic amyloidoses. N Engl J Med 1997; 337: 898-909.

2. Gillmore JD. Amyloidosis: a review of recent diagnostic and therapeutic developments. Br J Haematol 1997; 99: 245-256.

3. Kyle RA, Gertz MA. Primary systemic amyloidosis: clinical and laboratory features in 474 cases. Semin Hamematol 1995; 32: 45-49.

4. Merlini G. Treatment of Primary Amyloidosis. Semin Haematol 1995; 32: 60-79.

5. Zelis R, Mason DT, Barth W. Abnormal peripheral vascular dynamics in systemci amyloidosis. Ann Intern Med 1967; 70: 1167-1172.

6. Gertz MA, Kyle RA, Griffing WL, Hunder GG. Jaw claudication in primary systemic amyloidosis. Medicine 1986; 65: 173-179.

7. Salvarini C, Gabriel SE, Gertz MA, Bjornsson J, Li C-Y, Hunder GG. Primary systemic amyloidosis presenting as giant cell arteritis and polymyalgia rheumatica. Arthritis Rheum 1994; 37: 1621-1626.

8. Taillan B, Fuzibert JG, Vinti H, Perce A, Dujardin P. AL amyloid depo-

sits in temporal artery mimicking gianat cell arteritis. Clin Rheumatol 1990; 9: 256.

9. Lafforgue P, Senbel E, Figarella-Branger D, Boucraut J, Horschowsky N, Pellissier JF, et al. Systemic amyloidosis with temporal artery involvement revealing lymphoplasmacytic malignancy in a man presenting as polymialgia rheumatica. Ann Rheum Dis 1993; 52: 158-160.

10. Kyle RA, Greipp PR. Primary systemic amyloidosis: comparison of melphalan and prednisone versus placebo. Blood 1978; 52: 818-827.

11. Gertz MA, Kyle RA, Greipp PR. Response rates and survival in primary systemic amyloidosis. Blood 1991; 77: 257-262.

12. Kyle RA, Gertz MA, Greipp PR, Witzig TE, Lust JA, Lacy MQ, et al. A trial of three regimens for primary amyloidosis: colchicine alone, melpfhalan and prednisone, and melphalan, prednisone and colchicine. N Engl J Med 1997; 336: 1202-1207.

13. Gertz MA, Kyle RA. Amyloidosis: prognosis and treatment. Semin Arthritis Rheum 1994; 24: 124-138. 